\title{
Question-based Methodology for Rating the Severity of Defects in Construction Through on-Site Inspection
}

\author{
Bessa Rui*, Costa Jorge, and Calejo Rui \\ FEUP, Rua Dr. Roberto Frias, 4200-465 Porto, Portugal
}

\begin{abstract}
The impact of defects in construction is still not well-defined, and it is challenging to quantify all related indirect variables numerically. The majority of the studies in this field focus on the direct impact of defects on costs and planning, neglecting other indirect impacts that are more difficult to measure. Hence, it is vital to evaluate and classify the defects based on their impact, so that priorities can be defined for action both in their correction and prevention. In this work, a generalized methodology to grade the severity of defects was developed based on five impacts: impact on costs, planning, health and safety, system performance, and subsequent tasks.A suitable variant of failure modes and effects analysis (FMEA) was selected in order to develop a qualitative analysis methodology to grade the impact factors, severity, and risk prior number (RPN) of defects, based on question forms. Moreover, the presented methodology was applied on-site and compared with FMEA traditional severity calculations applied in the same construction project by the same individuals evaluating the same severity of defects. The obtained results from both methodologies were slightly different, and the authors believe that the identified tendency of different severity levels between both calculations could lead to different risk categories when applied to the whole project. Moreover, it is expected that the proposed methodology can also help separate the impacts for an individual evaluation of the defects.
\end{abstract}

Keywords: severity of defects; FMEA; impact of defects; construction defects; construction rework

(Submitted on May 11, 2019; Revised on June 20, 2019; Accepted on July 25, 2019)

(C) 2019 Totem Publisher, Inc. All rights reserved.

\section{Introduction}

Defects can have a significant impact on construction performance, contributing to cost and schedule overruns in construction projects [1]. Among other factors that restrain construction productivity, defect-related rework is considered as a non-value adding activity seriously affecting the performance and productivity in construction projects that spend unnecessary costs, time, materials, and workforce [2]. However, unlike causes, sources, and origins of defects, their impacts are not well-defined. In order to continuously improve quality and avoid the reoccurrence of defects, defect management (DM) in construction must take a more proactive approach [1]. The identification of costs and causes of quality shortcomings can provide management with information about process failures to prevent their future occurrence [3]. With the aim of reducing defects and rework, researchers have focused on a range of strategies such as studies identifying causes, magnitude, and cost of both construction and latent defects [4]. These researchers have analyzed information to get to the root of the problem by taking into account various perspectives, such as the type of defects, their frequency of occurrence, cost of repair, and defect source and origin. Efforts have been made in order to collect and classify defect information in real time using mobile and BIM technology.

Several studies report that rework costs could be significantly higher than the figures reported in some literature. Moreover, rework costs could be as high as $23 \%$ of the contract value [5]. Typically, research efforts have focused on determining direct rework costs at the expense of indirect costs, which remain relatively unknown [1]. Some authors have sought to address this imbalance and found that indirect costs can be as much as five times the cost of repair [6].

The actual significance of defects cannot be reflected only by cost, as the impact of the defects varies [7]. The analysis of the impact of defects is time-consuming and depends on many adequate variables that change depending on project type,

* Corresponding author.

E-mail address: rui@goupbuzz.com 
contract type, and value. Hence, a comprehensive methodology allowing the grading of the severity of defects that can be applied to all type of construction projects, irrespective of their characteristics, is needed [7].

\section{Short Literature Review}

Several studies focus on defect information management and classification. Sandberg [1] proposed a defect management framework according to PDCA methodology based on defect description. Other research has been focused on clustering defects by type, elements, category, sources, and origins, allowing for the identification of probable failure modes and their causes in each project. Aljassmi [8] performed a risk analysis on defect causes, while Forcada and Macarulla [4] standardized and classified Spanish housing defects. Similar works have been conducted on post-handover defects [6].

Hence, to define on-site action priority, an impact classification of defects is needed. In the past few years, several studies tried to quantify the real costs of rework on-site. Fayek [9] developed a field rework cost index that considered the direct and indirect costs. Love [10] quantified rework cost yielding from on-site non-conformances (NCR) and clustered defects by contract type, project type, and work type. Therefore, accurate data about the direct cost of rework is a very tedious and erroneous process, and the indirect costs are even more difficult to investigate.

For this reason, quantitative methods are not contextualized when the goal is to evaluate and prioritize efforts on the defects' corrective actions on-site. Few studies have put their effort into developing qualitative methods to classify defects on-site according to their severity. Pan [6] analyzed post-handover defects considering the severity level as the number of days during which defects needed attention. Moreover, Das and Chew [7] developed a severity grading system for maintainability decisions, applying FMECA and considering the economy, system performance, and safety impacts on defects. Thus, for better grading severity levels on defects, more variables need to be considered.

\section{Aim and Scope}

Defects can have an impact on both productivity and project performance level, influencing many variables beyond the economy, safety, and system performance. System performance evaluates the functions of a set of construction elements working together as parts of a mechanism.

Therefore, the collection and evaluation process should be direct and straightforward, allowing project and quality managers to classify defects on-site in a timely manner. This research aims to develop a qualitative method for grading the severity of defects according to the impact on cost, planning, safety and health, subsequent tasks, and system performance. Thus, an easy data collection method is proposed with question-based forms allowing for the assessment of the severity of defects on-site.

With this work, the following results are expected:

- To classify the severity of a defect in a standardized and systematic way;

- To prioritize defects and their corrective actions according to their severity level;

- To evaluate contractors' and subcontractors' performance during the construction phase;

- To allow for the clustering of defects by type, work, and subcontractor based on their severity level for future analysis;

- To allow for the implementation of preventive actions based on the previous clustering and analysis.

\section{Research Methodology}

In this research, five impact factors are considered in order to grade the defect's severity. These factors are divided into two groups: direct impact factors and indirect impact factors, where the last ones are considered as a multiplier of the first ones. A suitable variation of failure modes and effects analysis (FMEA) is selected after considering the aim, scope, and limitations of this study. Based on the adopted FMEA approach, a qualitative analysis method is developed in order to grade each impact factor, the severity of the defect, and the risk prior number (RPN). Moreover, the presented methodology is applied on-site and compared with the FMEA traditional severity calculation applied in the same construction project by the same people assessing the severity for the same defects. Conclusions are reached after the comparison of both methodologies. 


\section{Failure Mode Effects Analysis, Defects, and Rework}

\subsection{FMEA}

Failure modes and effects analysis (FMEA) is one of the risk analysis techniques recommended by international standards such as [11]. FMEA is a technique that is based on identifying potential failures, analyzing root causes, and examining failure impacts so that these impacts can be reduced. Within the context of the traditional FMEA, the degree of significance of a failure mode is determined by calculating the risk priority number (RPN). The RPN ranges from 1 to 1,000 and is an index score calculated as the product of the gradings of severity $(S)$, occurrence $(O)$, and detection $(D)$ of a failure mode. System components that are assessed to have a high RPN are assumed to be more critical than those with lower values. The severity rating $(S)$ is used to represent the potential effects associated with the occurrence of a failure mode. Thus, it reflects the seriousness of the effects of the failure. The occurrence rating $(O)$ is the frequency of the occurrence of the failure. Ayyub [12] defined the detection rating $(D)$ as "a measure of the capability of the current controls".

$$
R P N=S \times O \times D
$$

Within the traditional FMEA, a numerical scale ranging from 1 and 10 is used to represent the universe of standard situations for severity $(S)$, occurrence $(O)$, and detection $(D)$. Based on the values assigned to these terms, the value of the RPN is calculated. A suitable variation of FMEA was selected after considering the aim, scope, and limitations of this study. As the aim of this work is to evaluate the potential effects associated with the failure mode of the defects, the detection rating $(D)$ is not included in RPN calculation of this work once it is related to the capability of control, which depends on each organization and project.

\subsection{Definition of Defect}

The expressions "defect" and "nonconformity" have been used somewhat interchangeably in literature. In the ISO 9000 standards, a defect is defined as a "non-fulfillment of a requirement related to an intended or specified use" and is distinguished from nonconformity by being more severe and associated with liability issues [13]. ISO 9000 then defines quality as the "degree to which a set of inherent characteristics fulfills requirements", enabling quality to be measured quantitatively or by using a qualitative scale that could, for example, range from poor through good, to excellent [10].

Similarly, the expressions "rework" and "correction" describe the action applied to a nonconforming product to bring it into conformation with the requirements [10]. However, whereas correction refers to all types of modification of a nonconformity in order to achieve conformance (and, therefore, include features such as completing incomplete work, i.e., doing work for the first time), rework is preferably defined as "doing something at least one extra time due to nonconformance to requirements" [14].

Thus, rework also includes repair, i.e., "the process of restoring a non-conforming characteristic to an acceptable condition, even though the item may still not conform to the original requirement" [3].

\subsection{Rework Direct Costs}

Rework direct costs include errors that result in the rectification of works during construction. In this instance, costs arising from rework may be claimed by a contractor from a client, subcontractor, or designer, according to the explicit contractual terms and conditions, depending on which party is responsible for the rework.

To measure rework, direct and indirect costs performed on construction site must be considered. Direct costs are more easily obtained, as a combination of the following:

- Direct field labor and supervision;

- Materials;

- Equipment;

- Field contracts and subcontracts;

- Vendors and suppliers' costs of rework.

Rework costs are tracked from the point where rework is identified to the time when rework is completed and the activity has returned to the condition or state it was originally in. The duration of the cost tracking includes the length of the 
standby/relocation time once the rework is identified, the time required to carry out the rework, and the time required to gear up to carry on with the original scope of the activity. If the rework is done after the project has been delivered, the standby and gear up stage will not be considered. Figure 1 shows the rework cost tracking stages.

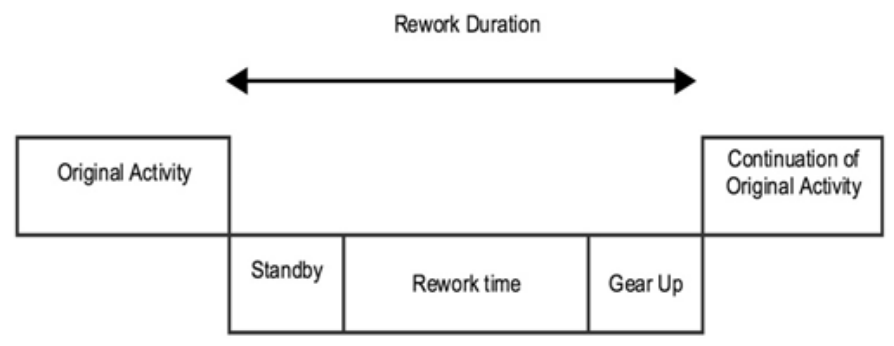

Figure 1. Rework costs tracking [9]

\subsection{Determinants of the Impact of Rework and Defects}

Differences in the definition of rework and the methods used for data collection indicate that rework costs could be significantly higher than the reported figures in literature [5].

Costs associated with failure arise from both internal and external sources. Internal failure costs are those incurred when rectifying an error or defect before a product leaves the organization or while it is still under its control. On the other hand, external failure costs are those incurred due to errors or defects in the product detected when the product has left the organization or is no longer under its control. Internal costs arising from poor quality increase the organization's cost of operations, such as through rework material waste and other avoidable process losses. However, external costs arising from poor quality result in loss of profits, including contractual claims, defect rectification (operational rework), and the loss of future business. Hence, the economic impact is far from being the only and most significant impact of defects and rework. At the productivity level, defects and rework can have an impact on:

- Morale level;

- Dilution of supervision;

- Conflict;

- Absenteeism;

- Fatigue;

- Communication.

From a project performance perspective, several other impacts may arise, such as:

- Cost;

- Time;

- Contractual claims;

- Client satisfaction;

- Team satisfaction;

- Contractor's satisfaction;

- Quality.

From the impacts shown above, the cost and schedule impact of defects deserve special attention, as they are usually possible to quantify and have direct effects on project quality. Thus, other factors can impact project quality and even indirectly affect the cost and planning of a project. In the next section, a brief definition of each impact factor used in this research will be made.

\subsection{Impact Factors Caused by Rework}

In the following section, the impact factors will be defined and explained as well as the effects to consider when grading their severity. Since this work aims to obtain a more realistic impact of defects based on other perspectives than direct costs and delays, it is considered that the other impact factors play the role of a multiplier for severity. The qualitative evaluation aims to consider indirect effects that each impact can have in defect severity, and it is not being considered in previous works. 


\section{- Impact on Costs:}

The impact on costs can be graded by measuring the direct cost of a defect, such as the workforce, materials, equipment, contract claims, and penalties as well as any other measurable cost that have a direct impact on the economic performance of the job. The other impact factors will contribute to a significant part of the unknown economic impact not considered in this grading. This impact factor aims to consider all impacts on costs, both internal and external. Rework can be performed when the product is already delivered and still counts as a defect cost (e.g. rectification or repair).

\section{- Impact on Planning:}

Delays coming from defects and rework time should be considered when rating this factor. Although delay penalties and rework time costs are already included in the economic impact, delays in schedule can impact in several other ways, and some of them cannot be measured even though they still increase the defects' severity. Delay time of a project should be the main factor when rating the impact on planning. Therefore, client satisfaction can impact positively or negatively the severity of a delay, as well as the contract conditions. Hence, these three factors should be weighted when rating this impact factor.

\section{- Impact on Health and Safety:}

The impact on costs and the planning impact of safety accidents have already been considered for previous impact factors [3, 7]. Therefore, safety accidents can also impact in many other ways than direct cost and schedule. A safety accident can affect productivity, morale, and trust and increase prevention costs, depending on its severity. Therefore, these side effects are not readily measurable or quantified. For this reason, the impact of a defect on health and safety is considered as an indirect effect in this methodology and will act as a multiplier factor of the direct impact factors mentioned above.

\section{- Impact on System Performance:}

System performance is another critical factor when grading severity. This impact factor rating is based on how the defect affects a system.

Therefore, this factor alone cannot provide enough information to classify a defect in terms of severity, because each system on construction has its relevance. Hence, the definition of a system can be very different from project to project, so a clear definition of the system taking a bottom-up approach is needed for each project. Hence, a complete loss of a system can be less relevant than a minor affected functionality on another system, depending on several other factors. For that reason, it is vital to rate system performance considering system relevance on the project scope. For its dependence, this impact factor is considered an indirect effect on the direct impact factors.

\section{- Impact on Subsequent Tasks:}

The impact of a defect on subsequent tasks deserves special attention because it can have a multiplier effect and generate potential indirect costs and schedule slippages that are very difficult to measure and quantify. Factors like the number of tasks affected, the severity of that influence, the number of different subcontracts affected, and the position of the affected tasks on project planning must be considered in order to rate the severity of a defect better. This factor paired with an impact on health and safety, as well as system performance, plays a multiplier role on the direct impact factors.

\section{The Proposed Methodology for Severity Grading}

\subsection{Initial Considerations}

A large variety of impact modes were shown in the previous section, but many of them cannot be quantified or measured due to their nature. Thus, they should be considered in order to determine the severity of defects, because some of them can be more important and costly than direct costs and effects.

As the severity of a defect is multidimensional, five impact factors are considered in order to rate the severity of defects better: 
- Impact on costs: accounts for all the direct costs caused by a defect during the operational phase, evolving rework costs (workforce, materials, equipment, etc.), contract claims, and insurances;

- Impact on planning: accounts for the total direct delay of a project during the construction phase caused by a defect;

- Impact on system performance: accounts for the system's loss due to a component/unit failure, based on its function, and detected during its performance checking;

- Impact on safety and health: accounts for the severity of an accident or fatality that occurred during the construction phase;

- Impact on subsequent tasks: accounts for all the collateral impact a defect can have on related tasks.

The direct impact of a defect on costs and planning is more accessible to measure and classify qualitatively, even on construction sites during the operational phase. However, according to the references in this research, considering only the direct impacts can lead to misinformation. In other words, irrespective of the direct impact on costs and planning that a defect may cause, other non-measurable side effects may reveal a higher severity than those initially considered. Other side effects are never measured, such as the low productivity caused by the occurrence of an accident at work.

For this reason, the authors consider in the proposed methodology a multiplier factor in calculating the defect's severity: the indirect impact multiplier (IIM). This multiplier is composed of three indirect impact factors, which are (i) the impact on system performance, (ii) the impact on safety and health, and (iii) the impact on subsequent tasks.

Each impact factor will be graded qualitatively according to the tables presented in Section 6.3, composing the final formula for the defect's severity. The authors expect that grading the impact of these factors will help consider the indirect effects they have on planning, costs, and quality, obtaining a more realistic severity grade for each defect.

In the following table, impact factors are presented with the effects to be considered when grading their severity. This methodology aims to be as flexible as possible and applicable to all kinds of systems and components. For that reason, the effects to be considered in this study are broad guidelines. It is desirable that the effects, as well as the grading boundaries presented in the next chapter, could be adapted to each project when applied. The considered impact factors as well as their effects are shown in Table 1.

\begin{tabular}{|c|c|l|}
\hline \multicolumn{2}{|c|}{ Table 1. Effects to consider for each impact factor } \\
\hline Defect impact factor & $\begin{array}{c}\text { Impact on project cost planning } \\
\text { and quality }\end{array}$ & Effects to consider \\
\hline Costs $(C)$ & Direct & $\bullet$ Workforce \\
& & $\bullet$ Materials \\
& & $\bullet$ Equipment \\
& & $\bullet$ Contractual claims and insurances \\
& & $\bullet$ Other direct costs \\
\hline Planning $(P)$ & Direct & $\bullet$ Project direct delay \\
& & $\bullet$ Contract conditions \\
& & $\bullet$ Client satisfaction \\
\hline Health and safety $(H S)$ & Direct and indirect & $\bullet$ Injury severity \\
& & $\bullet$ Preventive costs \\
\hline Subsequent tasks $(S T)$ & Direct and indirect & $\bullet$ Task position on project planning \\
& & $\bullet$ Number of conditioned tasks \\
& & $\bullet$ Level of conditioning \\
& & $\bullet$ Number of subcontracts affected \\
\hline System performance $(S P)$ & Direct and indirect & $\bullet$ System affection \\
& & $\bullet$ System relevance \\
\hline
\end{tabular}

As shown in Table 1, the effects can be divided into two groups: the effects that directly affect costs and project planning and the effects that indirectly affect planning and quality. In the next section, a grading methodology is presented from a qualitative approach in order to evaluate the severity of defects based on its direct and indirect impacts on project costs, quality, and planning.

\subsection{Grading Methodology}

Severity grading will be studied from a qualitative perspective, as the aim of this research is to develop a generic methodology that is easy to apply regardless of the assets and irrespective its characteristics. All factors are graded using a four-point scale for severity, as shown in Table 2. 
Table 2. Severity's grading scale

\begin{tabular}{|c|c|}
\hline Impact grading & Failure mode description \\
\hline 1 & No effect \\
\hline 2 & Minor effect \\
\hline 3 & Major effect \\
\hline 4 & Catastrophic effect \\
\hline
\end{tabular}

In order to guide the users to grade each impact easily, a question-based form should be developed for each impact factor. Thus, a careful preliminary analysis is required in the boundary definition of each grading scale for different projects, as well as in the division of the systems where this method is applied. For a more accurate grading, it will be desirable that more than one manager grades each impact factor, and the result will be the mean value of their answers.

\section{IFS $($ impact factor severity) $=$ Mean of all impact factor grading answers}

Some adjustments are recommended for each project in order to obtain better accuracy and quality data. The following steps explain the procedures to apply this method:

1) Choose the effects to be considered for each impact factor;

2) Level the rates for each impact factor and their respective effects;

3) Adapt the question-based forms according to effects and previously-selected grade levels;

4) Classify the defects using the forms in a possible standardized way, with possible opinions.

It is proposed that the direct impact factor $(D I F)$ is twice the maximum value between the cost impact factor $(C)$ and planning impact factor $(P)$ :

$$
D I F=2 \max (C ; P)
$$

Where DIF represents the direct impact factor, $C$ represents the impact on costs, and $P$ represents the impact on planning.

In order to classify the indirect effects multiplier (IEM), its calculation formula is considered as being the maximum value between 1 and 3 of the three indirect impacts considered previously. It can affect the severity of a defect up to $25 \%$ more than the initial assumption considering only direct costs and planning impacts.

$$
\begin{array}{lll}
\text { If } & \max (\mathrm{ST} ; \mathrm{HS} ; \mathrm{SP})=1 \Rightarrow \text { IEM }=1 \\
\text { else } & \max (\mathrm{ST} ; \mathrm{HS} ; \mathrm{SP})=2 \Rightarrow \text { IEM }=1,125 \\
\text { else } & \max (\mathrm{ST} ; \mathrm{HS} ; \mathrm{SP})=3=>\text { IEM }=1,25
\end{array}
$$

Where $S T$ represents the impact on subsequent tasks, $H S$ represents the impact on health and safety, $S P$ represents the impact on system performance, and IEM represents the indirect effect multiplier.

Finally, the severity of a defect $(S)$ will be the product between the direct impact factor and the indirect effect multiplier:

$$
S=D I F \times I E M, \text { Severity Calculation Proposal }
$$

Where $D I F$ represents the direct impact factor and IEM represents the indirect effect multiplier.

A numerical scale ranging from 1 and 10 is used to represent the universe of possible values for the severity $(S)$.

\section{Validation of the Proposed Methodology}

\subsection{Case Study Introduction}

In the following section, the developed methodology is tested on-site during the operational phase of a geotechnical project. Site engineers are chosen in order to qualify the defects' severities through the question base forms referred to in 6.3. The same site engineers are chosen to grade the same defects' severities through a suitable adoption of the traditional ten-point scale [15]. The first situation is identified as Case 1 and the second as Case 2 [16]. The defects' evaluations of Case 1 are identified as $\mathrm{d} 1, \mathrm{~d} 2, \cdots, \mathrm{d} 9$, and the defects in Case 2 are identified as $\mathrm{d}^{\prime} 1, \mathrm{~d}^{\prime} 2 \cdots, \mathrm{d}^{\prime} 9$. Nine defects are evaluated during the present case study through both methodologies. Both answers are used to calculate each RPN. Finally, both results are compared in order to identify the differences between them. 


\subsection{Grading Methodology}

As mentioned in Section 6.3, Case 1 must choose the effects to consider and the grading scale of severity. After that step, a question-based form is built for each impact factor, as shown in the next section.

\section{Question Form 1: Impact on Costs}

How did the defect impact the costs of the project? Impact on costs factor scale and its failure modes are presented below in Table 3 .

Table 3. Impact on costs form

\begin{tabular}{|c|c|}
\hline Impact on costs factor scale & Failure mode description \\
\hline 1 & No rework was needed \\
\hline 2 & Minor rework solved immediately \\
\hline 3 & $\begin{array}{c}\text { Rework needed with cost attribution to the contractor (<30\% } \\
\text { of initial task cost) }\end{array}$ \\
\hline 4 & $\begin{array}{c}\text { Major rework took by the contractor ( }>30 \% \text { of initial task } \\
\text { cost) }\end{array}$ \\
\hline
\end{tabular}

\section{Question Form 2: Impact on Project Planning}

How did the defect impact project planning? Impact on planning factor scale and its failure modes are presented below in Table 4.

Table 4. Impact on planning form

\begin{tabular}{|c|c|}
\hline Impact on planning factor scale & Failure mode description \\
\hline 1 & No schedule impact \\
\hline 2 & $\begin{array}{c}\text { Minor impact, possible to recover along with the project future } \\
\text { planning }\end{array}$ \\
\hline 3 & Minor impact on planning but impossible to recover \\
\hline 4 & Significant impact on planning, impossible to recover. \\
\hline
\end{tabular}

\section{Question Form 3: Impact on Subsequent Tasks}

How did the defect impact other project subsequent tasks? Impact on subsequent tasks factor scale and its failure modes are presented below in Table 5.

Table 5. Impact on subsequent tasks form

\begin{tabular}{|c|c|}
\hline Subsequent task impact factor scale & Failure mode description \\
\hline 0 & No impact on other tasks \\
\hline 1 & $\begin{array}{c}\text { Impact in other tasks not affecting the project critical path } \\
(\mathrm{CP})\end{array}$ \\
\hline 2 & Minor impact on tasks affecting the project critical path $(\mathrm{CP})$ \\
\hline 3 & Significant impact on tasks affecting project critical path \\
\hline
\end{tabular}

\section{Question Form 4: Impact on Health and Safety}

How did the defect impact the project health and safety? Impact on health and safety factor scale and its failure modes are presented below in Table 6.

Table 6. Impact on health and safety form

\begin{tabular}{|c|c|}
\hline Impact on health and safety factor scale & Failure mode description \\
\hline 0 & No impact related to health and safety \\
\hline 1 & Minor impact, solved immediately not causing any casualties \\
\hline 2 & A significant impact, causing casualties with no fatalities \\
\hline 3 & The occurrence of at least one fatality \\
\hline
\end{tabular}

\section{Question Form 5: Impact on System Performance}

How did the defect impact the considered system performance? Impact on system performance factor scale and its failure modes are presented below in Table 7. 
Table 7. Impact on system performance form

\begin{tabular}{|c|c|}
\hline Impact on system performance factor scale & Failure mode description \\
\hline 0 & $\begin{array}{l}\text { The defect did not affect system performance but may need a } \\
\text { corrective action }\end{array}$ \\
\hline 1 & $\begin{array}{l}\text { The defect damaged a system functionality, needing some } \\
\text { repair (re)work }\end{array}$ \\
\hline 2 & $\begin{array}{c}\text { The defect caused a loss of functionality on the system, } \\
\text { needing a partial replacement }\end{array}$ \\
\hline 3 & $\begin{array}{l}\text { The defect caused a complete system loss, with a need to redo } \\
\text { it from zero }\end{array}$ \\
\hline
\end{tabular}

In Case 2, a ten-point scale is chosen to rate severity, as shown on Table 8.

\begin{tabular}{|c|c|}
\hline Scale & $\begin{array}{c}\text { Table 8. Severity's ten-point scale } \\
\text { Not detected by customer }\end{array}$ \\
\hline 1 & $\begin{array}{c}\text { Slight failure, detected by the customer but no corrective } \\
\text { action is needed }\end{array}$ \\
\hline 2 & $\begin{array}{c}\text { Minor failure, with some visual impact but no corrective } \\
\text { action is needed }\end{array}$ \\
\hline 3 & $\begin{array}{c}\text { Minor impact, with moderate visual impact needing correction } \\
\text { if asked }\end{array}$ \\
\hline 4 & $\begin{array}{c}\text { Moderate impact, with significant visual impact needing } \\
\text { correction immediately }\end{array}$ \\
\hline 5 & $\begin{array}{c}\text { Moderate impact, affecting system performance, needing } \\
\text { correction immediately using light equipment }\end{array}$ \\
\hline 6 & $\begin{array}{c}\text { A significant impact, affecting system performance, needing } \\
\text { correction immediately using heavy equipment }\end{array}$ \\
\hline 7 & $\begin{array}{c}\text { A significant impact, affecting services performance, needing } \\
\text { correction immediately and public entities supervision }\end{array}$ \\
\hline 8 & Critical impact, affecting final building performance \\
\hline 9 & Critical impact with collapse and safety risk \\
\hline 10 &
\end{tabular}

In order to obtain the defect's probability of occurrence $(O)$, the number of inspections per task is considered, and the probability of occurrence is the number of defects detected among all inspections per task.

$$
\boldsymbol{O}=\boldsymbol{N} \times \boldsymbol{d}
$$

Where $\boldsymbol{N}$ is the number of inspections on a specific work and $\boldsymbol{d}$ is the number of defects detected on that work. Taking into account that ratio, a ten-point scale is developed for both Cases 1 and 2, as shown in Table 9.

Table 9. Probability of occurrence scale $(O)$

\begin{tabular}{|c|c|c|c|}
\hline Scale & $\begin{array}{c}\text { The certainty of the } \\
\text { event }\end{array}$ & $\begin{array}{c}\text { The probability of } \\
\text { occurrence }(O) \text { in } \\
\text { percentage }\end{array}$ & $\begin{array}{l}\text { The probability of occurrence } \\
\qquad(O) \text { in ratio }\end{array}$ \\
\hline 1 & Extremely unlikely & $<0,01 \%$ & $<1$ in 10000 \\
\hline 2 & Remote & $0,011-0,20 \%$ & 1 in 10000 \\
\hline 3 & Very low probability & $0,21-0,60 \%$ & 1 in 500 \\
\hline 4 & Low probability & $0,61-2 \%$ & 1 in 150 \\
\hline 5 & Occasional & $2,001-5,00 \%$ & 1 in 50 \\
\hline 6 & Moderate & $5,001-9,999 \%$ & 1 in 20 \\
\hline 7 & Frequent & $10,0-14,999 \%$ & 1 in 10 \\
\hline 8 & High probability & $15,0-19,999 \%$ & 1 in 6,5 \\
\hline 9 & Very high probability & $20,0-25,0 \%$ & 1 in 5 \\
\hline 10 & Failure almost inevitable & $>25 \%$ & $>1$ in 4 \\
\hline
\end{tabular}

\subsection{Results}

After grading both severity scales properly, results from Case 1 are compiled and calculated. All forms are answered by the same two site engineers, as shown in Table 10. 
Table 10. Proposed methodology: defect's severity $(S)$

\begin{tabular}{|c|c|c|c|c|c|c|c|c|c|c|c|c|c|c|}
\hline \multirow{2}{*}{$\begin{array}{l}\mathrm{C} \\
\mathbf{o} \\
\mathbf{d} \\
\mathrm{e}\end{array}$} & \multirow[t]{2}{*}{ Defect } & \multicolumn{2}{|c|}{$\begin{array}{c}\text { Impact on } \\
\text { costs }\end{array}$} & \multicolumn{2}{|c|}{$\begin{array}{c}\text { Impact on } \\
\text { planning }\end{array}$} & \multicolumn{2}{|c|}{$\begin{array}{c}\text { Impact on } \\
\text { H\&S }\end{array}$} & \multicolumn{2}{|c|}{$\begin{array}{c}\text { Impact on } \\
\text { subsequent } \\
\text { tasks }\end{array}$} & \multicolumn{2}{|c|}{$\begin{array}{c}\text { Impact on } \\
\text { system } \\
\text { performance } \\
\end{array}$} & \multirow{2}{*}{$\begin{array}{c}\begin{array}{c}\text { Direct } \\
\text { impact }\end{array} \\
D I F\end{array}$} & \multirow{2}{*}{$\begin{array}{c}\begin{array}{c}\text { Multiplier } \\
\text { effect }\end{array} \\
I E M\end{array}$} & \multirow{2}{*}{$\begin{array}{r}\begin{array}{r}\text { Defect } \\
\text { severity }\end{array} \\
S\end{array}$} \\
\hline & & Answer & $C$ & Answers & $P$ & Answers & $H S$ & Answers & $S T$ & Answers & $S P$ & & & \\
\hline $\mathrm{d} 1$ & $\begin{array}{c}\text { Poor } \\
\text { hydration of } \\
\text { the concrete }\end{array}$ & 2 & 1 & 2 & 1 & 2 & 1 & 2 & 1 & 2 & 2 & 2 & 1 & 2 \\
\hline $\mathrm{d} 2$ & $\begin{array}{l}\text { Insufficient } \\
\text { overcoating }\end{array}$ & 2 & 2 & 2 & 2 & 2 & 1 & 2 & 1 & 2 & 2 & 4 & 1,125 & 5 \\
\hline $\mathrm{d} 3$ & $\begin{array}{l}\text { Insufficient } \\
\text { steel bars } \\
\text { according } \\
\end{array}$ & 2 & 1 & 2 & 2 & 2 & 1 & 2 & 1 & 2 & 2 & 4 & 1,125 & 5 \\
\hline d4 & $\begin{array}{c}\text { Bad } \\
\text { deployment } \\
\text { of metal } \\
\text { profiles to } \\
\text { perform } \\
\text { corner struts } \\
\end{array}$ & 2 & 1 & 2 & 1 & 2 & 1 & 2 & 1 & 2 & 1 & 4 & 1 & 4 \\
\hline $\mathrm{d} 5$ & $\begin{array}{c}\text { Bad concrete } \\
\text { compaction }\end{array}$ & 2 & 2 & 2 & 2 & 2 & 1 & 2 & 1 & 2 & 2 & 4 & 1,125 & 5 \\
\hline d6 & $\begin{array}{c}\text { Wrong } \\
\text { deployment } \\
\text { of the } \\
\text { anchorages }\end{array}$ & 2 & 3 & 2 & 3 & 2 & 1 & 2 & 2 & 2 & 3 & 4 & 1,25 & 8 \\
\hline $\mathrm{d} 7$ & $\begin{array}{c}\text { Wrong } \\
\text { material for } \\
\text { the } \\
\text { waterproofing } \\
\text { system } \\
\end{array}$ & 2 & 2 & 2 & 1 & 2 & 1 & 2 & 1 & 2 & 3 & 4 & 1,25 & 5 \\
\hline $\mathrm{d} 8$ & $\begin{array}{c}\text { Deformed } \\
\text { armbars }\end{array}$ & 2 & 2 & 2 & 2 & & 1 & 2 & 1 & 2 & 2 & 4 & 1,125 & 5 \\
\hline d9 & $\begin{array}{c}\text { Bad } \\
\text { execution of } \\
\text { the } \\
\text { waterproofing } \\
\text { system of the } \\
\text { facade }\end{array}$ & 2 & 2 & 2 & 2 & 2 & 1 & 2 & 2 & 2 & 3 & 4 & 1,25 & 5 \\
\hline
\end{tabular}

After obtaining the severity values through the proposed methodology, the RPN is calculated through $(S)$ and $(O)$. The defect probability of detection $(D)$ is not considered in the calculation due to its difficulty to obtain on-site to make a practical evaluation of the detected defects. Table 11 shows the classification of defects in Case 1 , involving severity $(S)$, probability of occurrence $(O)$, and risk priority number $(R P N)$.

Table 11. Proposed methodology: defect's RPN

\begin{tabular}{|c|c|c|c|c|c|}
\hline Defect & Defect code & $\begin{array}{c}\text { Number of } \\
\text { occurrences detected }\end{array}$ & $S$ & $O$ & $R P N(S \times O)$ \\
\hline $\begin{array}{l}\text { Poor hydration of the } \\
\text { concrete }\end{array}$ & $\mathrm{d} 1$ & 9 & 2 & 10 & 20 \\
\hline Insufficient overcoating & $\mathrm{d} 2$ & 5 & 5 & 8 & 40 \\
\hline $\begin{array}{l}\text { Insufficient steel bars } \\
\text { according }\end{array}$ & $\mathrm{d} 3$ & 2 & 5 & 4 & 20 \\
\hline $\begin{array}{l}\text { Bad deployment of metal } \\
\text { profiles to perform corner } \\
\text { struts }\end{array}$ & $\mathrm{d} 4$ & 4 & 4 & 10 & 40 \\
\hline Bad concrete compaction & d5 & 2 & 5 & 4 & 20 \\
\hline $\begin{array}{l}\text { Wrong deployment of the } \\
\text { anchorages }\end{array}$ & d6 & 1 & 8 & 2 & 16 \\
\hline $\begin{array}{l}\text { Wrong material for the } \\
\text { waterproofing system }\end{array}$ & $\mathrm{d} 7$ & 1 & 5 & 2 & 10 \\
\hline Deformed armbars & $\mathrm{d} 8$ & 1 & 5 & 3 & 15 \\
\hline $\begin{array}{l}\text { Bad execution of the } \\
\text { waterproofing system of the } \\
\text { facade }\end{array}$ & d9 & 1 & 5 & 4 & 20 \\
\hline
\end{tabular}

In Case 2, the same probability of occurrence $(\mathrm{O})$ is used. Thus, the severity $(\mathrm{S})$ considered is based on the ten-point scale referred previously. Both methodologies' results are presented in Figure 2. 


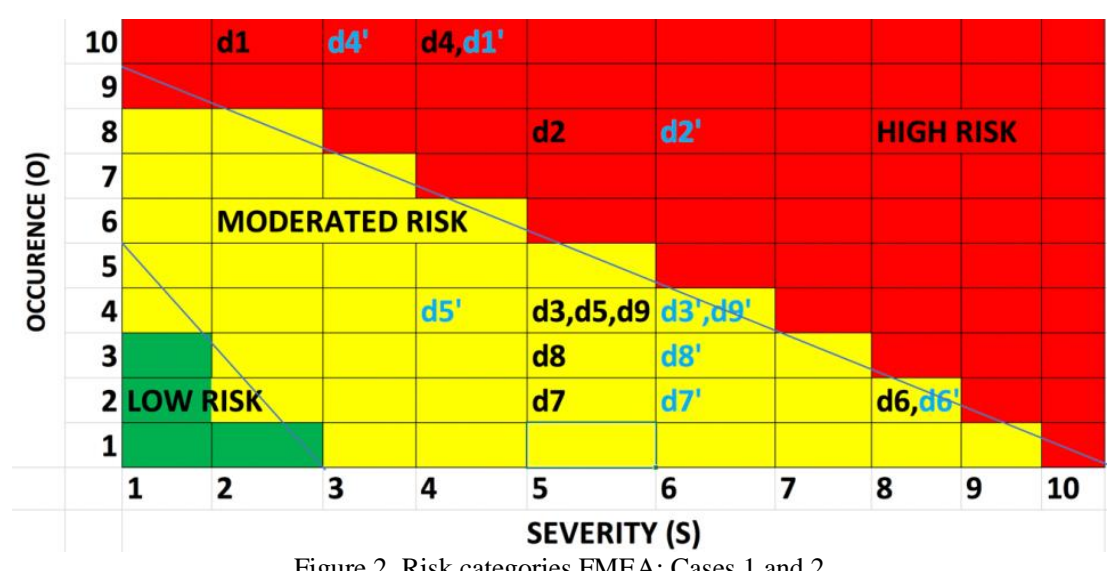

Figure 2. Risk categories FMEA: Cases 1 and 2

Defects identified by blue have their severity calculated from Case 2 methodology, while defects in black are obtained from the severity's proposed calculation methodology.

Overall, no significant defects were detected, as none of these defects were reported as a non-conformance on the company's quality management system certified according to ISO9000 standards.

The most severe defect was number six (d6 and d'6), which is wrong deployment of the anchorages disrupting a public water supply pipe. Defect d'2 reported a higher RPN (30), while both d2 and d4 reported a higher RPN in Case 1 (40). Different severity levels in both methodologies caused this difference.

In this case, both methodologies rated the same severity on this defect. The maximum deviation between the two methodologies was by two points in the severity scale and occurred on defects 1 and 7 . It is worth emphasizing that the same engineers evaluated the severity in both Cases 1 and 2 in the same period. As shown in Figure 2, only one out of the nine defects detected were evaluated with the same severity for both methodologies; however, the defect's risk categories (LOW, MODERATE, and HIGH) did not change.

\section{Conclusions and Further Considerations}

In order to discuss the results presented in this study, it should be considered that the defects tested are only a small sample of that project's defects; therefore, the authors believe that the identified tendency of different severity levels between Cases 1 and 2 could lead to different risk categories when applied for the whole project. These differences are due to a phased analysis that accounts for each factor independently and separates the direct and measurable impacts from the indirect impacts. The authors believe that the proposed methodology can also help separate the impacts for an individual evaluation. The site engineers interviewed in this case study found this question form methodology simple to fill on-site and very helpful as a guideline in order to evaluate a defect. For proper validation of the proposed methodology, further on-site applications in different project types are required.

\section{Acknowledgments}

This work was financially supported by UID/ECI/04708/2019 and FCT/MCTES (PIDDAC).

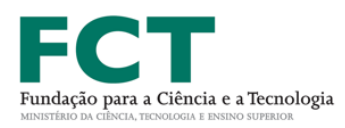

\section{References}

1. R. Lundkvist, "A Proactive Plan-Do-Check-Act Approach to Defect Management based on a Swedish Construction Project," Construction Management and Economics, Vol. 32, No. 11, pp. 1051-1065, 2014

2. C. S. Park, "A Framework for Proactive Construction Defect Management using BIM, Augmented Reality and Ontology-based Data Collection Template," Automation in Construction, Vol. 33, pp. 61-71, 2013

3. P. E. D. Love, "Revisiting Quality Failure Costs in Construction," American Society of Civil Engineers, 2017 
4. N. Forcada, M. Macarulla, M. Gangolells, M. Casals, A. Fuertes, and X. Roca, "Posthandover Housing Defects: Sources and Origins," Journal of Performance of Constructed Facilities, Vol. 27, No. 6, pp. 756-762, 2012

5. P. E. D. Love and J. Smith, "Benchmarking, Bench-Action, and Bench-Learning: Rework Mitigation in Projects," Journal of Management in Engineering, 2003

6. W. Pan and R. Thomas, "Defects and Their Influencing Factors of Posthandover New-Build Homes," Journal of Performance of Constructed Facilities, Vol. 29, No. 4, pp. 04014119, 2014

7. S. Das and M. Y. L. Chew, "Generic Method of Grading Building Defects using FMECA to Improve Maintainability Decisions," Journal of Performance of Constructed Facilities, Vol. 25, No. 6, pp. 522, 2011

8. H. Aljassmi and S. Han, "Analysis of Causes of Construction Defects using Fault Trees and Risk Importance Measures," Journal of Construction Engineering \& amp; Management, Vol. 139, No. 7, pp. 870, 2013

9. A. R. Fayek, "Measuring and Classifying Construction Field Rework: A Pilot Study," Construction Owners Association of Alberta (COAA) Field Rework Committee, 2003

10. P. E. D. Love and S. Sohal, “A Capturing Rework Costs in Projects,” Managerial Auditing Journal, Vol. 18, No. 4, 2003

11. MIL-STD-1629A, Military Standard: Procedures for Performing a Failure Mode, Effects, and Critically Analysis, 1980

12. B. M. Ayyub, "Risk Analysis in Engineering and Economics," pp. 33-113, Chapman \& Hall/CRC, New York, 2003

13. Swedish Standards Institute SS-EN ISO 9000:2005: Quality Management Systems - Fundamentals and Vocabulary, SIS Forlag, Stockholm, 2005

14. CIDA, Measuring Up or Muddling Through: Best Practice in the Australian Non-Residential Construction Industry, Construction Industry Development Agency, Australia, Master Builders Association, Sydney Australia, 1995

15. M. Villacourt, "Failure Mode and Effects Analysis (fmea): A Guide for Continuous Improvement for the Semiconductor Equipment Industry," International Semetech Inc., Austin, USA, 1992

16. L. Barroso, Construction Defects: Tree fault analysis and diagnosis Identification, FEUP, Dep. Construction, 2016 